\title{
LICENCIATURA EM ESTUDOS AFRICANOS E AFRO-BRASILEIROS: FORMAÇÃO DE PROFESSORES/AS EM DIREÇÃO À CONSTRUÇÃO DA JUSTIÇA CURRICULAR
}

\author{
Kátia Evangelista REGIS ${ }^{\mathrm{i}}$ \\ Cidinalva Silva Câmara NERIS ${ }^{\text {ii }}$
}

\begin{abstract}
RESUMO
No Brasil, a Lei $n^{\circ}$ 10.639/2003 tornou obrigatório o ensino da História e Cultura Africana e AfroBrasileira. Entretanto, são muitos os desafios para que a temática seja abordada com a seriedade, a rigorosidade e a complexidade necessárias, particularmente, na formação de professores/as nas Instituições de Ensino Superior, o que requer mudanças estruturais nos currículos dos cursos de Pedagogia e das demais licenciaturas. Nesse contexto, este artigo apresenta resultados do subprojeto de pesquisa "Formação de professores/as para o Ensino da História e Cultura Africana e Afro-Brasileira em uma perspectiva intercultural emancipatória", que integra a pesquisa "A justiça curricular no século XXI, as políticas e os sujeitos do currículo". Buscou-se analisar como as ações realizadas em trabalho de campo em Cabo Verde pelo curso de Licenciatura em Estudos Africanos e Afro-Brasileiros da Universidade Federal do Maranhão contribuem com a apreensão da História e Cultura Africana e AfroBrasileira em direção à construção da justiça curricular.
\end{abstract}

PALAVRAS-CHAVE: Formação de professores/as; Currículo; Ensino da História e Cultura Africana e Afro-Brasileira.

\section{DEGREE IN AFRICAN AND AFRO-BRAZILIAN STUDIES: TEACHER TRAINING IN DIRECTION TO THE CONSTRUCTION OF CURRICULAR JUSTICE}

\begin{abstract}
In Brazil, Law 10.639 / 2003 made the teaching of African and Afro-Brazilian History and Culture compulsory. However, there are many challenges for the subject to be approached with the seriousness, rigor and complexity necessary, particularly in the training of teachers in Higher Education Institutions,
\end{abstract}

\footnotetext{
' Graduada em História pela Universidade de São Paulo (USP), mestre e doutora em Educação: Currículo pela Pontifícia Universidade Católica de São Paulo (PUC-SP). Realizou pesquisa de pós-doutorado no Programa de Pós-Graduação em Educação: Currículo da PUC-SP em parceria com a Universidade Pedagógica de Moçambique. Docente e coordenadora da Licenciatura Interdisciplinar em Estudos Africanos e Afro-Brasileiros da Universidade Federal do Maranhão. E-mail: katia_educ@yahoo.com.br.

ii Possui graduação em História e mestrado em Ciências Sociais pela Universidade Federal do Maranhão e doutorado em Sociologia pela Universidade Federal de Sergipe, com estágio de doutoramento junto ao Institut des Sciences sociales du politique (ISP) / École Normale Supérieure de Cachan (ENS/Cachan). Docente da Licenciatura Interdisciplinar em Estudos Africanos e Afro-Brasileiros da Universidade Federal do Maranhão. E-mail: cidinalvasilva@yahoo.com.br.
} 
which requires structural changes in the curricula of pedagogy courses and degrees. In thiscontext, thisarticle presents results of there search subproject "Teacher Training for Teaching African and AfroBrazilian History and Culture in an Emancipatory Intercultural Perspective", which integrates there search "Curricular Justice in the 21st Century, Policies and the subjects of the curriculum. "The aim was to analyze how the actionscarried out in Fieldwork in Cape Verde by the Degree in African and Afro-Brazilian Studies of the Federal University of Maranhão contribute with the apprehension of African and Afro-Brazilian History and Culture towards the construction of justice curricular.

KEYWORDS: Teacher training; curriculum; Teaching of African and Afro-Brazilian History and Culture.

\section{GRADO EN ESTUDIOS AFRICANOS Y AFRO-BRASILEÑOS: FORMACIÓN DE PROFESORES EN DIRECCIÓN A LA CONSTRUCCIÓN DE JUSTICIA CURRICULAR}

\section{RESUMEN}

En Brasil, la Ley 10.639 / 2003 hizo obligatoria la enseñanza de la historia y cultura africana y afrobrasileña. Sin embargo, existen muchos desafíos para abordar el tema con la seriedad, el rigor y la complejidad necesarios, particularmente en la capacitación de docentes en instituciones de educación superior, lo que requiere cambios estructurales en los currículos de los cursos de pedagogía y grados En este contexto, este artículo presenta los resultados del subproyecto de investigación "Formación de docentes para la enseñanza de historia y cultura africana y afrobrasileña en una perspectiva intercultural emancipadora", que integra la investigación "Justicia curricular en el siglo XXI, políticas y las asignaturas del currículum ". El objetivo fue analizar cómo las acciones llevadas a cabo en Field work en Cabo Verde por el Grado en Estudios Africanos y Afrobrasileños de la Universidad Federal de Maranhão contribuyen a la aprehensión de la Historia y Cultura Africana y Afrobrasileña hacia la construcción de la justicia. curricular

PALABRAS CLAVE: Formación docente; Plan de estudios La enseñanza de la historia y cultura africana y afrobrasileña.

\section{INTRODUÇÃO}

O diálogo entre culturas é o grande desafio da educação das relações étnico-raciais. Como estabelecer diálogo entre distintas visões de mundo?

Como negociar mudanças? Como estabelecer metas e atingi-las, sem imposições? Que elos queremos criar? Que elos há que romper? Em se tratando de estabelecimentos de ensino, inclusive universitários, que pedagogias somos constrangidos a criar? Petronilha Beatriz Gonçalves e Silva (2018) 
No Brasil, a Lei $n^{\circ} 10.639 / 2003^{1}$, suas respectivas formas de regulamentação (a Resolução CNE/CP 01/2004 e o Parecer CNE/CP 03/2004) e todas as suas derivações legais de implementação tiveram o mérito de situar no cerne da discussão curricular a imediata inserção da História e Cultura Africana e Afro-Brasileira. Trata-se, pois, “[...] de política curricular, fundada em dimensões históricas, sociais, antropológicas oriundas da realidade brasileira", conforme as determinações das Diretrizes Curriculares Nacionais para a Educação das Relações Étnico-Raciais e para o Ensino de História e Cultura Afro-Brasileira e Africana (BRASIL, 2004, p.10).

A implantação de arcabouço legal pelo Estado brasileiro, a partir de 2003, com o objetivo de incluir a população negra brasileira a direitos antes alijados, marca uma mudança imprescindível para superar as desigualdades étnico-raciais com a adoção de políticas antirracistas, sobretudo na área educacional - um dos aspectos mais representativos no tocante ao combate das assimetrias existentes no Brasil. Tais resultados são consequências da luta empreendida pelo movimento negro brasileiro.

É fundamental, portanto, frisar o importante avanço jurídico-político ocorrido no país, que reconhece a legitimidade das lutas coletivas da população negra para a garantia do seu direito à educação de qualidade social: a Lei no 10.639/2003; a Lei nº 11.645/2008; as Diretrizes Curriculares Nacionais para a Educação das Relações Étnico-Raciais e para o Ensino de História e Cultura Afro-Brasileira e Africana (BRASIL, 2004); o Plano Nacional de Implementação das Diretrizes Curriculares Nacionais para a Educação das Relações ÉtnicoRaciais e para o Ensino da História e Cultura Afro-Brasileira e Africana (BRASIL, 2009); as Diretrizes Curriculares Nacionais para a Educação Escolar Quilombola (BRASIL, 2012) e a Lei $n^{\circ} 12.711 / 2012^{2}$.Destacamos esse arcabouço legal por ele representar a passagem dos debates realizados pelo social para o corpo jurídico, um movimento de reconhecimento de direitos fundamentais para a construção de uma sociedade justa, como evidencia Munanga (2015, p. 22):"No plano jurídico, o reconhecimento das identidades particulares no contexto nacional se configura como uma questão de justiça social e de direitos coletivos [...]".

Este processo está suscitando debates sobre o que é considerado valioso para ser transmitido nas instituições educacionais por meio dos seus currículos. Gimeno Sacristán (2013, p. 23) destaca que ao admitirmos que o currículo é uma construção, na qual são 
realizadas escolhas dentre as possibilidades existentes, uma questão emerge: "o que adotamos como conteúdo e o que deixamos de lado?". No Brasil, o currículo tem sido eurocêntrico e silencia e/ou desqualifica a História e Cultura Africana e Afro-Brasileira. Conforme Menezes (2019, p. 3), “[...] o eurocentrismo é um modo de pensar binário que constrói e promove uma identidade europeia, moderna e civilizada, justapondo-a a um habitante colonizado, subdesenvolvido, tradicional e bárbaro, habitante dos territórios periféricos ”. [...] Os conceitos eurocêntricos que permeiam as ciências sociais e humanas, a linearidade da narrativa teleológica do progresso em direção à civilização, impedem o reconhecimento dos sujeitos não-eurocêntricos, com conhecimento, produzindo teorias. O resultado desta operação é a transformação do projeto político europeu numa trajetória histórica supostamente universal. Deste modo, são muitos os desafios para que a História e Cultura Africana e Afro-Brasileira seja abordada com a seriedade, a rigorosidade e a complexidade necessárias, particularmente, na formação de professores/as nas Instituições de Ensino Superior (IES), o que requer mudanças estruturais nos currículos dos cursos de Pedagogia e das demais licenciaturas.

Nesse contexto de disputas em torno das discussões sobre a inclusão do tema, este artigo apresenta resultados do Subprojeto de Pesquisa "Formação de professores/as para o Ensino da História e Cultura Africana e Afro-Brasileira em uma perspectiva intercultural emancipatória”, que integra a pesquisa "A justiça curricular no século XXI, as políticas e os sujeitos do currículo”. Buscou-se analisar em que medida as ações realizadas em trabalho de campo em Cabo Verde pelo curso de Licenciatura em Estudos Africanos e Afro-Brasileiros (LIESAFRO) da Universidade Federal do Maranhão (UFMA) contribuem com a apreensão da História e Cultura Africana e Afro-Brasileira em direção à construção da justiça curricular. A referida atividade foi realizada entre 21 de novembro e 06 de dezembro de 2018 por 55 integrantes do curso (docentes, discentes, técnico-administrativa e bolsistas), 5 representantes da Secretaria de Educação do Estado do Maranhão (SEDUC-MA) e da Secretaria de Estado dos Direitos Humanos e de Participação Popular do Maranhão (SEDIHPOP-MA) ${ }^{3}$.

\section{A LEI No 10.639/2003: DESAFIOS E PERSPECTIVAS PARA O ENSINO DA HISTÓRIA E CULTURA AFRICANA E AFRO-BRASILEIRA}


A promulgação da Lei $\mathrm{n}^{\circ}$ 10.639/2003 favorece o reconhecimento, a valorização e a afirmação de direitos da população negra. Segundo as Diretrizes Curriculares Nacionais para a Educação das Relações Étnico-Raciais e para o Ensino de História e Cultura Afro-Brasileira e Africana (BRASIL, 2004), reconhecimento requer: justiça e igualdade de direitos sociais, civis, políticos, culturais e econômicos; valorização da história, cultura, identidade e memória da população negra, bem como a divulgação e o respeito aos processos históricos de resistência negra; mudanças de discursos, raciocínios, lógicas, gestos, posturas e no questionamento das relações étnico-raciais fundadas em preconceitos e estereótipos, que veiculam um falso sentimento de superioridade da população branca e de inferioridade da população negra. Para tanto, é fundamental desestabilizar o currículo eurocentrado para que a diversidade étnico-racial seja contemplada e para que o ensino da História e Cultura Africana e Afro-Brasileira seja estruturante das práticas curriculares em direção à justiça curricular. Segundo Torres Santomé (2016, p. 4),

La justicia curricular es el resultado de analizar el currículum que se legisla, diseña, pone en acción, evalúa e investiga, tomando en consideración el grado en el que todo lo que se decide y hace en las aulas es respetuoso y atiende a las necesidades y urgencias de todos los colectivos sociales; les ayuda a verse, analizarse, comprenderse y juzgarse en cuanto personas éticas, solidarias, colaborativas y corresponsables de un proyecto más amplio destinado a construir un mundo más humano, justo y democrático.

Partindo desse mesmo princípio, é fundamental a reflexão acerca do contexto político, social, econômico e cultural em que o currículo está inserido, bem como das disputas políticas em torno do que é considerado importante para ser ensinado nas instituições educacionais. Conforme Ponce (2018, p. 794),

Todo currículo implica um projeto de sociedade, de ser humano, de cultura. São perguntas que pautam propostas de currículos: que sociedade se deseja ter em futuro próximo e longínquo? Que pessoas são desejáveis na sociedade? Como formá-las? Com que valores éticos? Que conhecimentos são necessários para viver (dignamente) nesse mundo e para a construção de outro mundo possível?

Diferentes projetos de sociedade demandam diferentes formações.

As instigantes indagações levantadas pela autora corroboram as críticas que destacam que “[...] é indispensável se contrapor a processos de assimilação a pensamentos, 
comportamentos, projetos unicamente de raiz europeia [...]" (SILVA, 2018, p. 136).Tal perspectiva aponta a necessidade de profundas mudanças: nos modos pelos quais o currículo tem tratado a História e Cultura Africana e Afro-Brasileira; na representação da população negra nos livros didáticos ${ }^{4}$ e na transformação das relações interpessoais no cotidiano escolar que difundem normas, valores, comportamentos e atitudes preconceituosos e discriminatórios em relação à população negra, interferindo negativamente em seu desenvolvimento intelectual durante sua trajetória educacional.

As universidades brasileiras estão sendo cobradas a darem respostas que possam subsidiar mudanças para a realização de práticas curriculares em uma perspectiva intercultural ${ }^{5}$ e emancipatória - o que não é simples, pois implica na alteração do modo como, historicamente, os currículos escolares foram estruturados permancendo, ainda hoje, fundandos em uma concepção eurocêntrica, conforme apontam Coelho e Coelho (2018, p. 15), a partir da análise de dez projetospolítico-pedagógicos de licenciaturas em História em diferentes regiões do Brasil:

Salta aos olhos o volume do espaço europeu nos currículos de formação. A Europa é espaço absoluto de atenção em disciplinas voltadas para a compreensão de processos que nela ocorreram, como é o caso de História Antiga, História Medieval, História Moderna e História Contemporânea. Em seguida, a mesma Europa aparece como epicentro dos eventos que regulam processos em outras partes do globo - situação frequente em disciplinas voltadas para o trato com os processos de colonização da América (seja tratando do continente, nas disciplinas regularmente denominadas de História da América I, seja nas disciplinas voltadas para a abordagem da História do Brasil, identificadas, via de regra pelo numeral romano I), mas presentes também em disciplinas relativas à História da África, História Indígena, História da América ou do Brasil independentes e nas disciplinas de natureza teórico-metodológica. Nestas últimas, é meramente incidental a referência às perspectivas decoloniais que buscam estabelecer uma crítica à orientação eurocêntrica.

Esta constatação corrobora os resultados de uma ampla investigação, coordenada por Silva, Regis e Miranda (2018), que revela quão grandes são os desafios para que as instituições educacionais cumpram o arcabouço legal que legisla acerca da temática para a realização de práticas interculturais. A pesquisa definiu como objetivo geral sistematizar e analisar a produção acadêmica sobre educação das relações étnico-raciais entre 2003 e 2014 por meio da análise das teses e das dissertações realizadas nos programas de pós-graduação stricto sensu em 
Educação e dos periódicos Qualis A e B na área da Educação. A pesquisa selecionou 494 artigos, 476 dissertações e 122 teses da área de educação. Esse vasto levantamento do conhecimento produzido no Brasil sobre o tema revelou que um dos aspectos recorrente nas teses, nas dissertações e nos artigos investigados é o destaque para a necessidade de formação de professores/as que:

- Seja concretizada a partir de novos referenciais epistemológicos para a efetivação de uma educação intercultural;

- Subsidie revisão estrutural das propostas pedagógicas das instituições de ensino;

- Reflita em torno da prática profissional, considere as identidades e as subjetividades;

- Propicie a qualificação e o aprimoramento permanente dos/as professores/as, dos/as gestores/as, da equipe pedagógica e dos/as funcionários/as;

- Qualifique para o enfrentamento das situações de racismo, de preconceito racial e de discriminação racial no cotidiano escolar em todos os níveis, etapas e modalidades de ensino;

- Possibilite a desconstrução de conceitos e conteúdos preconceituosos e discriminatórios transmitidos por intermédio dos livros didáticos;

- Amplie e consolide os diálogos entre as universidades brasileiras e as africanas para a produção e a socialização de conhecimentos sobre o tema, com o desenvolvimento de pesquisas conjuntas.

A pesquisa apontou ainda, associada a esses processos formativos, a necessidade da criação e/ou ampliação de grupos de trabalhos nas secretarias estaduais e municipais de educação para o desenvolvimento e para a avaliação de ações acerca da Educação para as Relações Étnico-Raciais e para o ensino da História e Cultura Africana e Afro-Brasileira, bem como a articulação com outras políticas públicas que contemplem a diversidade étnico-racial brasileira.

Os resultados da investigação comprovam que, apesar do novo marco legal e normativo, são muitos os desafios para que as instituições educacionais realizem com propriedade o ensino da História e Cultura Africana e Afro-Brasileira, o que questiona de modo contundente as Universidades, em suas atividades de ensino, de pesquisa e de extensão e, muito especificamente, na formação de professores/as. No contexto de lutas e disputas políticas que 
interrogam as desigualdades étnico-raciais e realizam proposições para alterá-las, os currículos das universidades brasileiras estão sendo questionados para que possam subsidiar mudanças emancipatórias.

\section{LICENCIATURA INTERDISCIPLINAR EM ESTUDOS AFRICANOS E AFRO- BRASILEIROS: FORMAÇÃO DE PROFESSORES/AS EM UMA PERSPECTIVA INTERCULTURAL E EMANCIPATÓRIA}

Conforme o discutido anteriormente, ainda são muitos os desafios para que os processos de formação de professores/as abordem com a consistência adequada a História e Cultura Africana e Afro-Brasileira. Como uma das respostas à obrigatoriedade do ensino da temática nas IES, a UFMA implantou o curso de Licenciatura Interdisciplinar em Estudos Africanos e Afro-Brasileiros. Iniciativa pioneira no Brasil, realizada no estado com o maior percentual de população negra no país: 80,6\% (IBGE, 2016),teve início no dia 05 de maio de 2015, com a aula inaugural proferida pela então Ministra da Igualdade Racial, Profa. Dra. Nilma Lino Gomes.

O curso de Licenciatura Interdisciplinar em Estudos Africanos e Afro-Brasileiros tem como objetivo formar profissionais para a docência nos anos finais do ensino fundamental na área das Ciências Humanas (História, Geografia, Filosofia e Sociologia), no ensino médio na área de História e para atuação nas secretarias municipais e estaduais de educação para a implementação da Lei no 10.639/2003, de acordo com a Resolução nº 1657 - CONSEPE, 24 de outubro de 2017 (UFMA, 2017). O ingresso no curso ocorre anualmente por meio do Sistema de Seleção Unificada (SISU), pelo qual são oferecidas 40 vagas para o período noturno.

O processo formativo desenvolvido na LIESAFRO busca a interdisciplinaridade e a integração com a educação básica e com os movimentos sociais, o que ocorre por meio dos seus eixos interdisciplinares; das Práticas de Ensino como Componente Curricular (PECCs) de suas disciplinas; dos projetos de iniciação à docência como o Residência Pedagógica e o Programa Institucional de Bolsas de Iniciação à Docência(PIBID); e das Semanas Interdisciplinares de Estudos Africanos e Afro-Brasileiros realizadas periodicamente. No sentido de viabilizar a realização da formação proposta, a LIESAFRO tem buscado parceiros, como é o exemplo do 
Termo de Cooperação Técnico-Científica estabelecido com a SEDUC-MA, que será discutido na seção seguinte.

A Licenciatura em Estudos Africanos e Afro-Brasileiros tem como base uma matriz curricular disciplinar inserida em uma perspectiva interdisciplinar. Tal concepção vem atender ao que dispõe a Resolução $n^{\circ} 02$, de $1^{\circ}$ de julho de 2015, que dentre os princípios da Formação de Profissionais do Magistério da Educação Básica, determina que seja realizado: VII - um projeto formativo nas instituições de educação sob uma sólida base teórica e interdisciplinar que reflita a especificidade da formação docente, assegurando organicidade ao trabalho das diferentes unidades que concorrem para essa formação.

Nessa configuração, o curso promove momentos de integração das disciplinas que, geralmente, são trabalhadas na educação básica de forma dispersa e sem conexão entre si. Busca-se na LIESAFRO superar a fragmentação do ensino, possibilitando uma educação integral e holística e uma formação de professores/as que, em sua prática profissional, vise à valorização do/a educando/a e a transformação social.

O curso busca, nesse sentido, contribuir para que a interdisciplinaridade se torne uma prática efetiva por meio de ações que articulam ensino, pesquisa e extensão. Compromete-se, desse modo, com práticas que se configuram como indispensáveis para uma formação de qualidade social, democrática e que seja baseada na valorização das diversas formas de resistência e existência do povo negro, bem como da diversidade de conhecimentos produzidos pelos diferentes grupos étnico-raciais que compõem a população brasileira. Segundo Freire (1998, p. 39-40), “A prática preconceituosa de raça, de classe, de gênero, ofende a substantividade do ser humano e nega radicalmente a democracia”.

$\mathrm{Na}$ aproximação desse compromisso com a interdisciplinaridade, é imprescindível o movimento de integração entre as disciplinas ao mesmo tempo em que se suscita um procedimento de atualização/revisão de cada uma delas. Por isso, a proposta curricular da LIESAFRO caminha na direção de novas relações entre as disciplinas, o que possibilita a ampliação de espaços de intercâmbios dinâmicos e de experiências político-pedagógicas mais inovadoras. Em suma, entrelaça saberes e pessoas, provoca o diálogo, revisa relações com o conhecimento (FAZENDA, 2008; SEVERINO, 2008). 
Nessa perspectiva, a LIESAFRO prevê que em cada ano letivo exista um eixo interdisciplinar: $1^{\circ}$ ano: Literatura Africana e da Diáspora; $2^{\circ}$ ano: Cinema Africano e da Diáspora; $3^{\circ}$ ano: Grandes Pensadores/as Africanos/as e da Diáspora; $4^{\circ}$ ano: Políticas Antirracistas no Mundo. Esses eixos temáticos articuladores servem de orientação à atuação de todos/as os/as docentes, que realizam reuniões de planejamento no início de cada semestre para elaborarem a relação das obras que serão utilizadas obrigatoriamente por todos/as eles/as com base em uma abordagem interdisciplinar, além das referências relacionadas nas ementas de cada disciplina ofertada no semestre.

Os eixos interdisciplinares devem ser cumpridos obrigatoriamente pelos/as estudantes e ocorrerão anualmente de forma sequencial para que, na integralização da Licenciatura em Estudos Africanos e Afro-Brasileiros, todos/as os/as discentes possam ter a oportunidade de cursá-los. A articulação entre as diferentes áreas do conhecimento para o desenvolvimento desses eixos temáticos ocorre por intermédio das discussões realizadas em cada disciplina e em atividades como seminários, exibição de filmes, saraus, exposições, apresentações artísticas, entre outras atividades planejadas coletivamente pelo corpo docente, discente e técnicoadministrativo do curso ${ }^{6}$.

Para a divulgação das produções feitas no âmbito do curso e para propiciar um espaço de discussão de pesquisadores/as nacionais e internacionais que se articulam na produção acerca dos Estudos Africanos e Afro-Brasileiros, uma iniciativa importante da LIESAFRO foi a criação da Kwanissa - Revista de Estudos Africanos e Afro-Brasileiros, em 27 de março de $2018^{7}$. Seu conselho editorial e científico reúne professores/as de várias instituições do Brasil e do mundo, com nomes importantes e que estão produzindo reflexões de referência na área.

\section{TRABALHO DE CAMPO EM CABO VERDE: (DES)CONSTRUINDO CONHECIMENTO ACERCA DA HISTÓRIA E CULTURA AFRICANA E AFRO- BRASILEIRA $^{8}$}

A Lei $\mathrm{n}^{\circ}$ 10.639/2003 intenciona possibilitar o reconhecimento e a valorização das raízes africanas no país, ao lado das raízes indígenas, asiáticas e europeias. Para tanto, são imprescindíveis mudanças substanciais no processo de formação inicial dos/as professoras/es

Kátia Evangelista REGIS, Cidinalva Silva Câmara NERIS Licenciatura em estudos africanos e afro-brasileiros: formação de professores/as em direção à construção da justiça curricular 
nos cursos de Pedagogia e nas demais licenciaturas, para que este processo problematize e altere as visões preconceituosas sobre a África e permita aos/às estudantes brasileiros/as perceberem que o Continente Africano não é homogêneo, tampouco o interior dos países que o compõem. Nesse sentido, Torres Santomé (2013, p. 9-10) destaca que:

Comprometer-se com uma educação crítica e libertadora obriga a investigar em que medida os objetivos, os conteúdos, os materiais curriculares, as metodologias didáticas e os modelos de organização escolar respeitam as necessidades dos distintos grupos sociais que convivem em cada sociedade. [...] é preciso julgar o grau em que as teorias educativas que embasam as propostas curriculares com as quais se trabalha são o resultado de levar em conta as vozes dos "outros", suas necessidades, perspectivas e esperanças.

O conhecimento veiculado nas instituições educacionais não pode ser sinônimo de eurocentrismo, como se fosse, naturalmente, a indicação do que é importante para ser ensinado e não o resultado de uma construção histórica. O desconhecimento da África pelos brasileiros/as é consequência de todo um longo e brutal processo de dominação cultural que constituiu o eurocentrismo como única forma de se apreender o mundo, invisibilizando a riqueza do conhecimento produzido em outros espaços e em outras bases de pensamento.

Um dos aspectos que consideramos importante para problematizar essa episteme diz respeito à ampliação e à consolidação de redes internacionais de pesquisa que estabeleçam diálogos entre as universidades brasileiras e as dos diferentes países, especialmente, americanos e africanos. A partir dessa compreensão, a Licenciatura em Estudos Africanos e AfroBrasileiros vem estabelecendo intercâmbios com universidades africanas para viabilizar o desenvolvimento de pesquisas e ações conjuntas que ofereçam novos fundamentos epistemológicos para superar os desafios postos à implementação da Lei no 10.639/2003 e que possibilitem superar visões estereotipadas e preconceituosas acerca do Continente Africano.Com a articulação de diferentes áreas de conhecimento, é possível ampliar, consolidar e socializar as pesquisas e os materiais bibliográficos e audiovisuais sobre a História e Cultura Africana que podem contribuir para a realização de uma educação intercultural e emancipatória.

Essa percepção impulsionou a concretização do Termo de Cooperação TécnicoCientífica com a SEDUC-MA, que viabilizou o trabalho de campo em Praia/Cabo Verde, entre 21 de novembro e 6 de dezembro de 2018, de 55 integrantes (docentes, discentes, técnicoadministrativa e bolsistas) da LIESAFRO e de 5 representantes da SEDUC-MA e da 
SEDIHPOP. Em contrapartida, a Licenciatura em Estudos Africanos e Afro-Brasileiros realizará a formação para 500 professores/as do Estado do Maranhão em 2019. Esta parceria possui os seguintes objetivos:

- Propiciar a apreensão de novos fundamentos epistemológicos para que o ensino da História e Cultura Africana e Afro-Brasileira seja realizado a partir de uma perspectiva intercultural emancipatória em direção à justiça curricular;

- Debater acerca das políticas antirracistas no mundo para contribuir com a formulação e com a implementação de políticas públicas que efetivem a igualdade étnico-racial no Estado do Maranhão;

- Possibilitar aos/às participantes do Trabalho de Campo em Cabo Verde um intercâmbio de conhecimentos sobre a História e a Cultura Africana e da Diáspora de maneira interdisciplinar;

- Estimular a produção de pesquisas conjuntas entre os/as investigadores/as da Universidade Federal do Maranhão e da Universidade de Cabo Verde (Uni-CV);

- Contribuir para a elaboração e para a execução deprojetos e ações educativas sobre a História e Cultura Africana e Afro-Brasileira nas escolas estaduais do Maranhão;

- Realizar a formação de 500 professores/as da educação básica e de 50 gestores/as das políticas de promoção da igualdade racial no Estado do Maranhão.

No decorrer dos quinze dias do trabalho de campo foram realizadas diversas atividades em diferentes espaços da Ilha de Santiago. A comitiva visitou a Associação Kobon; estabeleceu diálogos institucionais; realizou visitas guiadas na Fundação Amílcar Cabral, no Museu Histórico Nacional, na Biblioteca Nacional, no Presídio do Tarrafal, no Forte de São Filipe e na Cidade Velha; participou de roda de conversa na Biblioteca Nha Balila, localizada no bairro Tira Xapéu; realizou reuniões técnicas entre investigadores/as brasileiros/as e caboverdianos/as; participou de reunião no Ministério da Educação de Cabo Verde e do I Colóquio Internacional Políticas Antirracistas no Mundo, em parceria com a Universidade de Cabo Verde (Uni-CV).

O diálogo entre o Brasil e Cabo Verde, por intermédio do trabalho de campo em Praia, favoreceu o alargamento e o adensamento da fundamentação teórica necessária para que o que é ensinado sobre a História e Cultura Africana e Afro-Brasileira seja construído a partir de bases 
sólidas da ancestralidade africana e por meio de parcerias com educadores/as e pesquisadores/as africanos/as. Esse intercâmbio trouxe contribuições decisivas acerca de referências sobre os temas do que se ensinar sobre a África Ocidental no Brasil e, particularmente, sobre Cabo Verde, a partir do intercâmbio de conhecimento para viabilizar a construção de práticas curriculares em direção à construção da justiça curricular. Segundo Ponce e Neri (2015, p. 333, grifos nossos),

A justiça curricular se faz pela busca e prática do currículo escolar como instrumento de afirmação da superação de desigualdades; sendo a prática curricular a chave desse processo nas suas três dimensões fundamentais: a do conhecimento necessário para que os sujeitos do currículo se instrumentalizem para compreender o mundo e a si mesmos nele; a do cuidado com esses sujeitos envolvidos no processo pedagógico de modo a garantir que todos tenham condições dignas para desenvolver-se; e a da convivência democrática e solidária que deve ser promovida pela escola e vivenciada nela e fora dela.

A intenção do curso foi de propiciar ações em diálogo com a Uni-CV, com os movimentos sociais e com as instituições governamentais. Nesse sentido, nosso primeiro encontro teve como fundamento trocas culturais com a Associação Kobon, que nos apresentou o bairro de mesmo nome no qual fica localizada, originado de um antigo lixão, na cidade de Praia. Esta experiência foi muito rica para toda a comitiva por apresentar uma realidade de luta e de resistência tão próxima da nossa em um local tão distante, como expresso pelo estudante L.:

No bairro Kobon e Vila Nova foi possível perceber que a luta pela moradia existe em qualquer canto do planeta em que as desigualdades sociais e a especulação imobiliária se fazem presente. Também, através da visita ao Bairro Kobon, foi possível ver como nossas culturas tem proximidades. Ao ouvirmos o Batuque (um dos ritmos musicais mais antigos) percebemos o quão está próximo do nosso Tambor de Crioula aqui de São Luís.

Essa diversidade de atividades proporcionou um espaço de discussão e de construção do conhecimento acerca da temática e contribuiu para refletir e oferecer subsídios para a implementação efetiva da Lei $n^{\circ} 10.639 / 03$, que legisla sobre a obrigatoriedade do ensino da História e Cultura Africana e Afro-Brasileira. Esta afirmação tem como base a pesquisa que 
realizamos com todos os/as 35 estudantes da comitiva, por meio da aplicação de questionário e de relatórios entregues pelos/as discentes. Destacamos algumas das questões do questionário, respondido entre os dias 10 e 20 de dezembro de 2018:

- $\quad$ A estadia em Cabo Verde propiciou o conhecimento sobre a história e a cultura de Cabo Verde e da África Ocidental? De que maneira?

- $\quad$ Em que medida o trabalho de campo em Cabo Verde contribuirá para a sua atuação na docência sobre a História e Cultura Africana e Afro-Brasileira?

- Qual aspecto da viagem você destacaria como fundamental para a sua formação?

- Qual relação você poderia destacar entre o que foi aprendido nas disciplinas do curso e o trabalho de campo realizado em Cabo Verde?

De modo geral, as respostas nos levaram a concluir que o trabalho de campo foi extremamente enriquecedor e superou as expectativas para o processo formativo dos/as estudantes ao possibilitar a apreensão da história, da cultura, das relações sociais, políticas e econômicas a partir da vivência do cotidiano cabo-verdiano e por intermédio das atividades organizadas em parceria com a Uni-CV, como conferências, oficinas e visitas guiadas.

As diversas atividades realizadas promoveram a aproximação com uma realidade social que só era conhecida por meio de intermediários e por aproximações teóricas, possibilitando aos/às docentes e aos/às discentes da LIESAFRO uma reflexão sobre os instrumentos analíticos e os conceitos a que temos acesso para refletir sobre a complexidade das sociedades africanas, como podemos notar nos depoimentos seguintes:

As pautas abordadas no Colóquio Internacional de Políticas Antirracistas foram de grande valia para o nosso processo de produção de conhecimento. Explorar nossa ancestralidade nos permitiu materializar todo nosso conhecimento teórico adquirido das disciplinas ministradas no curso até o momento (L. R.) ${ }^{9}$.

Vivenciar o cotidiano em um país africano foi fantástico, não só para confrontar as nossas pesquisas teóricas, mas também, a nossa própria construção social, cultural e histórica(R.).

[...] principalmente a não ver o continente africano com um olhar romantizado e piedoso (A.C.). 
Uma das contribuições mais destacadas pelos/as estudantes refere-se à quebra dos estereótipos preconceituosos sobre Cabo Verde e o Continente Africano. Esta questão é de grande valor na medida em que demonstra a importância do fortalecimento da produção de conhecimento sobre a África que tenha como fundamento a superação dos essencialismos e de uma leitura consensual do mundo.

[...] as experiências vivenciadas em Cabo Verde foram essenciais para o processo de desconstrução de estereótipos sobre a África, mais precisamente o contexto cabo-verdiano. A estadia nos possibilitou presenciar o dia-a-dia, a cultura, a linguagem, os discursos construídos por influência de um processo histórico, a culinária. Todo este conjunto nos ajuda a reconstruir e perceber as complexidades existentes na construção histórica e social cabo-verdiana (A. P.).

[...] creio que o aspecto fundamental é ter uma mudança de pensamento com relação ao que é África, desconstruir conceitos de uma África apenas pobre e precarizada (G.).

É fundamental para o ensino da História e Cultura Africana e Afro-Brasileira a produção de um conhecimento crítico sobre o Continente Africano em interação com o Brasil, que seja embasado no contato entre essas distantes, mas, tão próximas realidades. Tal experiência evidencia ainda o quanto a efetivação das atividades de ensino, pesquisa e extensão é fundamental na formação docente ao propiciar ao/à formando/a a produção de conhecimento por meio da articulação entre os conteúdos discutidos nas disciplinas e as vivências a partir do contato com a realidade estudada e sobre a qual irá lecionar. Assim, os/as estudantes do curso puderam (re)formular olhares sobre Cabo Verde e sobre a África Ocidental que haviam construído no decorrer das disciplinas do curso.

Durante nossa estadia no país, foi possível construir é desconstruir vários conceitos que já tínhamos antes da chegada de nossa comitiva na Cidade de Praia (L. R.).

Acredito que a relação de parceria entre teoria e prática foi de fundamental importância (N.).

Acredito que esta viagem foi fundamental para minha formação em todos aspectos, pois estudamos o lugar que estava na rota do tráfico de escravizados, servia de ponto de apoio para os traficantes negreiros, isto é muito relevante para uma formação em Estudos Afro-Brasileiros, a historiografia do Brasil perpassa pela historiografia de Cabo Verde. Pude constatar isto lendo alguns 
livros escritos por lá, o Brasil aparece em todos que vi. O suporte epistemológico acessado durante essa estadia em Cabo Verde é de extrema importância para nossa formação (M. I.).

O dia a dia com a cultura, os saberes locais, a língua, o trato com as pessoas tanto no âmbito acadêmico como nas comunidades, cada um com suas perspectivas, nos fazem refletir sobre a realidade de nosso país e a importância do nosso curso e da nossa formação, para que nossos jovens com o estudo da História Africana e Afro-Brasileira possam ir mudando o país em que vivem por meio dos ensinamentos apreendidos (M. C.).

Ao fazer esse trabalho de campo foi possível reconhecer assuntos vistos em sala de aula da mesma forma interdisciplinar, que vão da geografia aos movimentos sociais, quando viajamos do centro da cidade até Cidade Velha, onde teve início a colonização do continente, vendo a situação das barragens para armazenamento de água, agricultura, comércio, etc. (T.).

A estudante C.P. destacou o quão enriquecedor foi estar na Cidade Velha, a primeira capital do arquipélago de Cabo Verde:

São vários aspectos, mas a possibilidade de ter visitado a Cidade Velha foi muito enriquecedor. Oriunda da diáspora africana, consegui, por meio dessa oportunidade, completar uma lacuna que por anos estava incompleta. Todos nós temos uma história que nos antecede. Para quem não é negro no Brasil e tem maior poder aquisitivo preencher lacunas de sua história consiste em uma tarefa fácil, entretanto para o negr(@) pobre é bem difícil essa possibilidade. Portanto, estar em Cabo Verde, Cidade Velha, foi pisar no local que meus ancestrais estiveram antes de partir para as Américas e RESISTIRAM, logo, um dos inícios da minha história. Assim, essa viagem tem uma dimensão incalculável para mim, que transcende uma formação acadêmica, é algo ainda maior que acalenta minha alma diaspórica africana.

C.P., hoje graduada em Estudos Africanos e Afro-Brasileiros, fala da História e Cultura Africana e Afro-Brasileira consciente de sua multiplicidade, de sua complexidade e dos diversos processos de desterramento, de opressão, mas, também, de resistência que vêm acompanhando a população negra brasileira desde o período colonial e que tem na organização curricular de nosso sistema de ensino, seja na educação básica, seja no ensino superior, a reprodução de uma sociedade injusta, preconceituosa e, sobretudo, racista. Uma estrutura curricular que naturaliza o racismo, que invisibiliza a população negra, negando-lhe o papel de sujeitos na construção da sociedade brasileira. Conforme Munanga (2012, p. 10), 
Essa história, mal a conhecemos, pois ela foi contada doponto de vista do "outro", de maneira depreciativa e negativa. Reencontrar o fio condutor da verdadeira história do Negro que o liga à África sem distorções e falsificações. A consciência histórica, pelo sentimento de coesão que cria, constitui uma relação de segurança mais sólida para cada povo. É a razão pela qual cada povo faz um esforço para conhecer e viver sua verdadeira história e transmitila para as futuras gerações. Razão pela qual o afastamento e a destruição da consciência histórica era uma das estratégias utilizadas pela escravidão e colonização, para destruir a memória coletiva dos povos escravizados e colonizados.

Qual é o lugar imposto à negra e ao negro brasileiros? Que tipo de conhecimentos lhes são ofertados? Porque é negado à população brasileira o acesso à diversidade de saberes dos quais somos herdeiros desde África e que somaram-se aos saberes das populações que habitavam este país antes da chegada dos/as europeus? Como podemos superar essa estrutura? Essas questões são importantes para refletirmos sobre as posturas que nós, professoras e professores, podemos e devemos tomar frente a esse quadro que nega a nossa história e folcloriza a Cultura Africana e Afro-Brasileira, pois, as Diretrizes Curriculares Nacionais para a Educação das Relações Étnico-Raciais e para o Ensino de História e Cultura Afro-Brasileira e Africana (BRASIL, 2004) determinam a importância de a história da África ser tratada de maneira positiva, articulada à história da população negra no Brasil.

É fundamental um posicionamento político para construir estratégias de resistência para que a existência da população seja (re)conhecida pelos demais grupos étnico-raciais que formam nossa sociedade. Uma existência que não pode ser subsumida apenas à escravidão, mas que, apesar desta, que tem como um dos marcos principais a passagem por Cabo Verde, permanece em cada um de nós. Segundo Gomes (2012, p. 105),

[...] a mudança estrutural proposta por essa legislação abre caminhos para a construção de uma educação anti-racista que acarreta uma ruptura epistemológica e curricular, na medida em que torna público e legítimo o "falar" sobre a questão afro-brasileira e africana. Mas não é qualquer tipo de fala. É a fala pautada no diálogo intercultural. E não é qualquer diálogo intercultural. É aquele que se propõe ser emancipatório no interior da escola, ou seja, que pressupõe e considera a existência de um "outro", conquanto sujeito ativo e concreto, com quem se fala e de quem se fala. E nesse sentido, incorpora conflitos, tensões e divergências. Não há nenhuma "harmonia" e nem "quietude" e tampouco "passividade" quando encaramos, de fato, que as diferentes culturas e os sujeitos que as produzem devem ter o direito de 
dialogar e interferir na produção de novos projetos curriculares, educativos e de sociedade.

C.P. fala de uma lacuna herdada de sua formação escolar. Sua fala evidencia o quanto a ausência da história da África e do africano/a na formação histórica do Brasil, o silenciamento da própria história da C.P., marcou sua formação identitária. Percebemos ainda a importância da LIESAFRO em seu processo de (re)encontro com sua história, com o passado de seus ancestrais e de (re)construção de si mesma. Essa mesma situação é vivenciada por tantas outras crianças negras, durante suas trajetórias educacionais, a quem, assim como ocorreu com C.P., é negado o direito de conhecer sua própria história, como temos presenciado no decorrer das atividades que docentes e discentes da Licenciatura em Estudos Africanos e Afro-Brasileiros vêm desenvolvendo na educação básica.

No decorrer das atividades realizadas pela LIESAFRO nas escolas públicas de São Luís, vemos o quanto a ausência de referências negras nos conteúdos escolares leva a interpretações equivocadas sobre o Continente Africano e sobre os/as afro-brasileiros/as. O movimento realizado pelo curso, saindo dos muros da universidade, promovendo experiências de ensino, de pesquisa e de extensão, seja na periferia de São Luís, seja em outro continente, são necessárias para uma formação docente que busque uma educação de qualidade social e uma sociedade mais equitativa na qual todos/as tenham o direito de conhecer sua própria história. Foi nesse sentido que os/as estudantes expressaram a contribuição do trabalho de campo em Cabo Verde para sua atuação docente:

O Trabalho de Campo em Cabo Verde com certeza contribuirá para minha atuação na docência sobre a História e Cultura Africana e Afro-Brasileira. Isso se traduz na possibilidade de poder estar falando de África embasada na experiência de ter pisado no continente, o que para essa área da docência é uma forma enriquecida de estar desmistificando algumas compreensões acerca da História africana e, por conseguinte, da cultura afro-brasileira (C. P.).

Para além do arcabouço teórico, a vivência em Cabo Verde é essencial para uma maior compreensão das complexidades reais existentes no mundo global pós-colonial. Desta forma, a estadia no continente africano torna-se essencial para futuras discussões na docência (A. P.).

A partir da observação e contato direto com um país africano poderei passar para@s alun@s algo mais concreto, mais vivo sobre a História e Cultura 
Africana e, dessa forma, poder sair da teoria do livro, e assim passar e passear pela História com mais leveza (N.).

Vivenciar o cotidiano em um país africano foi fantástico, não só para confrontar as nossas pesquisas teóricas, mas também a nossa própria construção social, cultural e histórica. Na atuação docente este Trabalho de Campo será indispensável, visto que agregará vivência aos conteúdos estudados em sala de aula. Este trabalho possibilitará desconstruir muitos estereótipos sobre a África e sobre a cultura afro-brasileira (R.).

É importante destacarmos que a participação no trabalho de campo realizado pela LIESAFRO em Cabo Verde coaduna-se com a obrigatoriedade do estudo da História e da Cultura Africana, na medida em que retrata um esforço no sentido de: executar as atribuições previstas para as instituições de ensino superior no Plano Nacional de Implementação das Diretrizes Curriculares Nacionais para a Educação das Relações Étnico-Raciais e para o Ensino da História e Cultura Afro-Brasileira e Africana (BRASIL,2009), que destaca que as instituições públicas de ensino superior devem realizar ações acadêmicas, encontros, jornadas e seminários para promover relações étnico-raciais positivas para seus/uas estudantes, bem como promover pesquisas, desenvolvimento e inovações tecnológicas sobre o tema.

\section{CONCLUSÃO}

O rompimento de uma estrutura curricular eurocêntrica, racista e excludente como a brasileira não é fácil. Exige investimentos em múltiplas frentes, principalmente em uma formação de professores/as que busquem (re)conhecer a existência da diversidade epistemológica e desmistificar a unidade de saberes como apresentada pela ciência moderna. Do mesmo modo, requer o envolvimento de diversos sujeitos, dentre os quais as universidades desenvolvem papel preponderante. Foi a partir de tais circunstâncias que apresentamos aqui as experiências da Licenciatura Interdisciplinar em Estudos Africanos e Afro-Brasileiros da UFMA e as ações que vêm se desenvolvendo em direção à construção da justiça curricular por meio da valorização das relações dinâmicas entre universidade/comunidade, entre a universidade e educação básica e as redes de intercâmbio para produção e socialização de conhecimentos entre o Brasil e o Continente Africano na formação docente. 
A perspectiva epistemológica e as ações desenvolvidas pela LIESAFRO aqui apresentadas, principalmente, no que diz respeito à sua estrutura curricular que valoriza um ensino interdisciplinar, em comunicação com a educação básica e as atividades realizadas em Cabo Verde corroboram uma perspectiva política de educação emancipatória e crítica, que valoriza a diversidade de saberes e dos sujeitos do currículo. Retratam as possibilidades de realização, dentro e fora da universidade, de uma educação transformadora que exprima, não apenas a diversidade epistemológica, mas a valorize como parte importante das nossas práticas sociais, questionando as hierarquias de saberes que fundamentam as diversas formas de exclusão às quais os/as africanos/as, americanos/as, afro-brasileiros/as e afro-americanos/as são expostos na prática curricular hegemônica.

Desta feita, as experiências analisadas neste artigo relatam uma proposta curricular que intenciona superar as desigualdades e promovera equidade. Isto significa valorizar a riqueza da diversidade étnico-racial brasileira, situando a população negra no lugar que lhe é de direito: como sujeito e não objeto da história. Resulta, pois, que a construção da justiça curricular é possível na medida em que promovamos a produção de conhecimento e a formação de professores/as que reconheçam a diversidade dos sujeitos e dos saberes, permitindo que educandos/as e educadores/as sintam-se e reconheçam a todos como integrantes e elaboradores de saberes produzidos e compartilhados.

\section{REFERÊNCIAS}

BRASIL. Lei no 9.394, de 20 de dezembro de 1996. Estabelece as Diretrizes e Bases da Educação Nacional. Disponível em: http://www.planalto.gov.br/ccivil 03/leis/19394.htm. Acesso em: Acesso em: 15 fev. 2019.

BRASIL. Lei $\mathbf{n}^{\mathbf{0}} \mathbf{1 0 . 6 3 9}$, de 9 de janeiro de 2003. Altera a Lei $\mathrm{n}^{\circ}$ 9.394, de 20 de dezembro de 1996, que estabelece as Diretrizes e Bases da Educação Nacional, para incluir no currículo oficial da Rede de Ensino a obrigatoriedade da temática "História e Cultura Afro-Brasileira", e dá outras providências. Disponível em: http://www.planalto.gov.br/ccivil 03/leis/2003/110.639.htm. Acesso em: Acesso em: 15 fev. 2019.

BRASIL. Diretrizes Curriculares Nacionais para a Educação das Relações ÉtnicoRaciais e para o Ensino de História e Cultura Afro-Brasileira e Africana. Brasília: MEC/SEPPIR, 2004. Disponível em: http://portal.inep.gov.br/informacao-da-publicacao/- 
lasset publisher/6JYIsGMAMkW1/document/id/488171. Acesso em: Acesso em: 18 fev. 2019.

BRASIL. Lei $\mathbf{n}^{\mathbf{0}}$ 11.645, de 10 de março de 2008. Altera a Lei ${ }^{\circ}$ 9.394, de 20 de dezembro de 1996, modificada pela Lei $\mathrm{n}^{\mathrm{o}}$ 10.639, de 9 de janeiro de 2003, que estabelece as Diretrizes e Bases da Educação Nacional, para incluir no currículo oficial da rede de ensino a obrigatoriedade da temática "História e Cultura Afro-Brasileira e Indígena". Disponível em: http://www.planalto.gov.br/ccivil 03/ Ato2007-2010/2008/Lei/L11645.htm. Acesso em: Acesso em: 18 fev. 2019.

BRASIL. Plano Nacional de Implementação das Diretrizes Curriculares Nacionais para a Educação das Relações Étnico-Raciais e para o Ensino de História e Cultura AfroBrasileira e Africana. Brasília: SECAD; SEPPIR, 2009. Disponível em: http://www.crianca.mppr.mp.br/arquivos/File/publi/mec/diretrizes_curriculares_etnicorraciais mec 2013.pdf. Acesso em: Acesso em: 15 fev. 2019.

BRASIL. Diretrizes Curriculares Nacionais para a Educação Escolar Quilombola. 2012. Disponível em: http://portal.mec.gov.br/programa-mais-educacao/323-secretarias112877938/orgaos-vinculados-82187207/18694-educacao-quilombola-sp-1000400393. Acesso em: Acesso em: 15 fev. 2019.

BRASIL. Lei $\mathbf{n}^{\mathbf{0}}$ 12.711, de 29 de agosto de 2012. Dispõe sobre o ingresso nas universidades federais e nas instituições federais de ensino técnico de nível médio e dá outras providências. Disponível em: http://www.planalto.gov.br/ccivil 03/ ato2011-2014/2012/lei/112711.htm. Acesso em: Acesso em: 15 fev. 2019.

BRASIL. Resolução n ${ }^{\mathbf{0}}$ 2, DE $1^{\text {o }}$ DE JULHO DE 2015. Define as Diretrizes Curriculares Nacionais para a formação inicial em nível superior (cursos de licenciatura, cursos de formação pedagógica para graduados e cursos de segunda licenciatura) e para a formação continuada. Disponível em: http://portal.mec.gov.br/docman/agosto-2017-pdf/70431-res-cnecp-002-03072015-pdf/file. Acesso em: 15 fev. 2019.

BRASIL. Conselho Nacional da Educação. Institui Diretrizes Curriculares Nacionais para a Educação das Relações Étnico-Raciais e para o Ensino de História e Cultura Afro-Brasileira e Africana. Resolução no 01 de 17 de junho de 2004. Brasília, DF, 2004. Disponível em: http://portal.mec.gov.br/pnaes/323-secretarias-112877938/orgaos-vinculados82187207/12988-pareceres-e-resolucoes-sobre-educacao-das-relacoes-etnico-raciais. Acesso em: 03 abr. 2018.

COELHO, Wilma de Nazaré Baía; COELHO, Mauro Cézar. As Licenciaturas em História e a Lei 10.639/03 - percursos de formação para o trato com a diferença? Educação em Revista, v.34, p. 1-39 , 2018. Disponível em: http://www.scielo.br/pdf/edur/v34/1982-6621-edur-34e192224.pdf. Acesso em: 15 fev. 2019.

FAZENDA, Ivani. O que é interdisciplinaridade? São Paulo: Cortez Editora, 2008. 
FREIRE, Paulo. Pedagogia da Autonomia: saberes necessários à prática educativa. 8. ed.São Paulo: Paz e Terra, 1998.

GOMES, Nilma Lino. Relações étnico-raciais, educação e descolonização dos currículos. Currículo sem Fronteiras, v.12, n.1, jan./abr., p. 98-109, 2012. Disponível em: http://www.curriculosemfronteiras.org/vol12iss1articles/gomes.pdf. Acesso em: 20 set. 2015.

IBGE. Síntese de Indicadores Sociais: Uma análise das condições de vida da população brasileira. 2016. Disponível em: https://biblioteca.ibge.gov.br/visualizacao/livros/liv98965.pdf. Acesso em: 15 fev. 2019.

MENESES, Maria Paula. Colonialismo, governaçãoe a história: porque a ignorância arrogante recusa dialogar com o Sul Global - Alice Comenta. Alice News, 16jul. 2019. Disponível em: https://alicenews.ces.uc.pt/index.php?lang=1\&id=25936. Acesso em:20 jul. 2019.

MÜLLER. Tânia Mara Pedroso. A produção acadêmica sobre a imagem do negro no livro didático: Estado do Conhecimento (2003-2013). Anais da 37 Reunião Anual da Associação Nacional de Pós-Graduação e Pesquisa em Educação, Grupo de Trabalho no 21 "Educação e Relações Étnico-Raciais". 2015. Disponível em: http://37reuniao.anped.org.br/wp-content/uploads/2015/02/Trabalho-GT21-3684.pdf. Acesso em: 15 jan. 2016.

MUNANGA; Kabengele. Negritude e identidade negra ou afrodescendente: um racismo ao avesso? Revista da ABPN, vol. 4, n. 8, p. 06-14, jul.-out. 2012. Disponível em: http://abpnrevista.org.br/revista/index.php/revistaabpn1/article/view/246/222. Acesso em: 09 de julho de 2019.

MUNANGA; Kabengele. Por que ensinar a história da África e do negro no Brasil de hoje? Revista do Instituto de Estudos Brasileiros, n. 62, p. 20-31, dez 2015. Disponível em: http://www.scielo.br/pdf/rieb/n62/2316-901X-rieb-62-00020.pdf. Acesso em: 10 mar. 2019.

PONCE, Branca Jurema; NERI, Juliana F. O currículo escolar em busca da justiça social: a violência doméstica contra a criança e o adolescente. Revista e-Curriculum, São Paulo, v. 13, n.2, p. 331-349, 2015. Disponível em:

https://revistas.pucsp.br/index.php/curriculum/article/view/23663. Acesso em: 12 maio de 2018.

PONCE, Branca Jurema. O currículo e seus desafios na escola pública brasileira: em busca da justiça curricular. In: Currículo sem Fronteiras, v. 18, n. 3, p. 785-800, set./dez. 2018. Disponível em: http://www.curriculosemfronteiras.org/vol18iss3articles/ponce.pdf. Acesso em: 10 jun. 2109. 
SILVA, Tatiana Raquel Reis. A arte de comerciar: gênero, identidades e emancipação feminina no comercio transatlântico das rabidantes em Cabo Verde. 2012. 156 f. Tese (Doutorado em Estudos Étnicos e Africanos) CEAO, Universidade Federal da Bahia, Salvador, 2012. Disponível em: https://repositorio.ufba.br/ri/handle/ri/24068. Acessado em 30 ago. 2019

GIMENO SACRISTÁN, José.O que significa o currículo? In: SACRISTÁN, J. Gimeno (Org.). Saberes e incertezas sobre o currículo.Porto Alegre: Penso, 2013, p. 16-35.

SANTOS, Boaventura de Sousa. A gramática do tempo: para uma nova cultura política. 3 ed. São Paulo: Cortez, 2010.

SEVERINO, Antônio Joaquim. O conhecimento pedagógico e a interdisciplinaridade: o saber como intencionalização da prática. In: FAZENDA, Ivani. (Org). Didática e interdisciplinaridade. 13. ed. Papirus: Campinas, 2008, p. 31-44. Disponível em: https://educfacil.files.wordpress.com/2012/11/ivani-fazenda-didc3a1tica-einterdisciplinaridade.pdf. Acessado em 30 ago. 2019.

SILVA, Paulo Vinicius Baptista da; TEIXEIRA, Rozana; PACÍFICO, Tânia Mara. Políticas de promoção de igualdade racial e programa de distribuição de livros didáticos. Educação e Pesquisa, v. 39, n. 1, p. 127-143, jan.-mar. 2013. Disponível em: http://www.scielo.br/pdf/ep/v39n1/v39n1a09.pdf. Acesso em: 15 mar. 2018.

SILVA; Paulo Vinícius Baptista; REGIS, Kátia; MIRANDA, Shirley (Orgs). Educação e Relações Étnico-Raciais: o Estado da Arte. Curitiba: NEAB-UFPR, 2018.

SILVA, Petronilha Beatriz Gonçalves e. Educação das Relações Étnico-Raciais nas instituições escolares. Educar em Revista. Dossiê Educação e Relações Étnico-Raciais: o Estado da Arte. Curitiba, Brasil, v. 34, n. 69, p. 123-150, maio/jun. 2018. Disponível em: https://revistas.ufpr.br/educar/article/view/58097. Acesso em: 14 mar. 2019.

TORRES SANTOMÉ, Jurgo. Currículo escolar e justiça social: o cavalo de Troia da educação. Porto Alegre: Penso, 2013.

TORRES SANTOMÉ, Jurgo. Justicia curricular y laurgencia de volver a repensar elcurrículum escolar. Intervenciónen el Coloquio: Curriculum - Sociedad: Voces, Tensiones yPerspectivas.México DF, 11, 12, 13 y 14 de Octubre, 2016. Disponível em: https://jurjotorres.com/?p=5127. Acesso em: $20 \mathrm{dez} .2018$.

UFMA. RESOLUÇÃO Nº 1657 - CONSEPE, São Luís, 2017. 


\section{NOTAS}

${ }^{1}$ A Lei $\mathrm{n}^{\mathrm{o}}$ 11.645, de 10 de março de 2008, altera a LDB 9394/96, anteriormente modificada pela Lei $\mathrm{n}^{\circ}$ 10.639/2003, para incluir no currículo oficial da rede de ensino a obrigatoriedade da temática "História e Cultura Afro-Brasileira e Indígena".

${ }^{2}$ A Lei n ${ }^{\circ} 12.711$, de 29 de agosto de 2012, determina que: Art. $1^{\circ}$ As instituições federais de educação superior vinculadas ao Ministério da Educação reservarão, em cada concurso seletivo para ingresso nos cursos de graduação, por curso e turno, no mínimo 50\% (cinquenta por cento) de suas vagas para estudantes que tenham cursado integralmente o ensino médio em escolas públicas. Parágrafo único. No preenchimento das vagas de que trata o caput deste artigo, $50 \%$ (cinquenta por cento) deverão ser reservados aos estudantes oriundos de famílias com renda igual ou inferior a 1,5 salário-mínimo (um salário-mínimo e meio) per capita. [...] Art. $3^{\circ}$ Em cada instituição federal de ensino superior, as vagas de que trata o art. $1^{\circ}$ desta Lei serão preenchidas, por curso e turno, por autodeclarados pretos, pardos e indígenas, em proporção no mínimo igual à de pretos, pardos e indígenas na população da unidade da Federação onde está instalada a instituição, segundo o último censo do Instituto Brasileiro de Geografia e Estatística (IBGE).

${ }^{3} \mathrm{O}$ trabalho de campo em Cabo Verde foi financiado pelo Governo do Estado do Maranhão por meio de Termo de Cooperação Técnico-Científica entre a LIESAFRO e a SEDUC-MA. A parceria também prevê a formação de 500 professores/as da educação básica do Estado do Maranhão e de 50 gestores/as de políticas para a promoção da igualdade racial no segundo semestre de 2019. A escolha de Cabo Verde para realização do trabalho de campo deveu-se à possibilidade de fortalecimentos das pesquisas já em andamento entre docentes da LIESAFRO e pesquisadores/as da Uni-CV, constituindo assim uma rede de pesquisas que vem se ampliando com a integração de investigadores/as de outras regiões do Brasil e de outros países africanos, por meio da realização de termos de cooperação técnica entre a UFMA e outras universidades africanas e brasileiras.

${ }^{4}$ Sobre a representação da população negra nos livros didáticos ver Müller (2015) e Silva, Teixeira e Pacífico (2013).

${ }^{5}$ De acordo com Santos (2010, p. 152), “[...] as perspectivas interculturais têm vindo a permitir o reconhecimento da existência de sistemas de saberes plurais, alternativos à ciência moderna ou que com esta se articulam em novas configurações de conhecimentos. Analisando de forma crítica a ciência como garantia da permanência do estatuto hegemônico do actual sistema econômico capitalista, os autores que perfilham esta crítica têm vindo a lutar por uma maior abertura epistémica, no sentido de tornar visíveis campos de saber que o privilégio epistemológico da ciência tendeu a neutralizar, e mesmo ocultar, ao longo dos séculos".

${ }^{6}$ Os resultados desse trabalho interdisciplinar são socializados, por exemplo, por meio da organização dos seguintes eventos realizados pelo curso: Semana Interdisciplinar dos Estudos Africanos e Afro-Brasileiros - 13 a 17 de julho de 2015; II Semana Interdisciplinar dos Estudos Africanos e Afro-Brasileiros "Literatura Africana e Afro-Brasileira" - 4 a 8 de abril de 2016;III Semana Interdisciplinar dos Estudos Africanos e Afro-Brasileiros "Literatura Africana e Afro-Brasileira" - 15 a 19 de agosto de 2016; IV Semana Interdisciplinar dos Estudos Africanos e Afro-Brasileiros "OcupAfro" - 6, 7 e 13 de dezembro de 2016; V Semana Interdisciplinar dos Estudos Africanos e Afro-Brasileiros “África em suas múltiplas linguagens" - 17 a 21 de julho de 2017; VI Semana Interdisciplinar dos Estudos Africanos e Afro-Brasileiros "Mulheres Negras, Militância e Produção do Conhecimento" - 20 a 24 de novembro de 2017. Durante as semanas interdisciplinares todos/as estudantes apresentam comunicações orais, pelas quais socializam os resultados dos trabalhos desenvolvidos nos eixos.

${ }^{7}$ Kwanissasignifica, no idioma Sena de Beira (Moçambique), resista, aguente firme. O endereço da Kwanissa é: http://www.periodicoseletronicos.ufma.br/index.php/kwanissa/index

${ }^{8}$ Cabo Verde é um país insular, formado por dez ilhas, que está localizado na região central do Oceano Atlântico. Sua origem está ligada à expansão europeia do século XV. Conforme destaca Andrade (1995) apud Silva (2012), os portugueses objetivavam promover o povoamento branco, assim como haviam feito nos Açores e na Ilha da Madeira. No entanto, o arquipélago foi povoado, lentamente, por escravizados, originários das diversas etnias que habitavam a Costa da Guiné, empregados na criação de animais e na agricultura. Esse modo de povoamento das ilhas deu origem a uma população crioula que caracteriza a sociedade atual.

${ }^{9}$ Por princípios éticos da pesquisa identificaremos os/as participantes do estudo pelas iniciais de seus nomes.

Kátia Evangelista REGIS, Cidinalva Silva Câmara NERIS Licenciatura em estudos africanos e afro-brasileiros: formação de professores/as em direção à construção da justiça curricular 
Enviado em: 21/07/2019

Aprovado em: 31/08/2019 